\title{
Комбинационное рассеяние циркулярно поляризованного света на оптических фононах Si
}

\section{Талочкин А.Б.}

ИФП СО РАН, 630090, Новосибирск, пр. Ак. Лаврентьева, 13

DOI 10.34077/Semicond2019-63

Применение циркулярно поляризованного (ЦП) света для возбуждения спектров комбинационного рассеяния (КР), как показано недавно $[1,2]$, открывает новую степень свободы метода КР - возможность наблюдения углового момент (УМ) фононов. Поскольку ЦП фотон имеет УМ, то в процессе КРС должен выполняться закон его сохранения. УМ возбуждающего фотона распределяется между рассеянным фотоном и фононом. Это позволяет регистрировать фононы, имеющие УМ. Данный метод применялся недавно в 2D материалах $\mathrm{MoS}_{2}, \operatorname{ReS}_{2}$ и др. [1,2].

Интенсивность КР линейно поляризованного (ЛП) света определяется тензором $\mathrm{R}_{\alpha \beta}$, который зависит от симметрии кристалла и наблюдаемого фонона. Он используется для КР ЦП светом в представлении Джонса [1,2]. Этот подход в общем случае вызывает сомнение, поскольку тензор КР получен из классического анализа, в котором понятие УМ отсутствует. Наблюдение КР ЦП светом в простом и ясном случае (Si) позволит прояснить основные особенности этого метода.

В данной работе исследованы угловые зависимости интенсивности КР ЛП и ЦП света на оптических фононах Si. Измерения проводились при $\mathrm{T}=300 \mathrm{~K}$ в геометрии обратного рассеяния от плоскостей (100), (111) и (110) Si. Спектры возбуждались линией $\mathrm{Ar}$ лазера с $\lambda=488$ нм. На рис.1 показаны зависимости, полученные для (100) и (111) ориентаций. Кривые, наблюдаемые для ЛП (рис.1), хорошо согласуются с результатами, полученными из тензора КР: $I_{(100)} \sim(\cos \varphi)^{2}, I_{(111)} \sim(\sin \varphi)^{2}$ $+(2 / 3)(\cos \varphi)^{2}$.

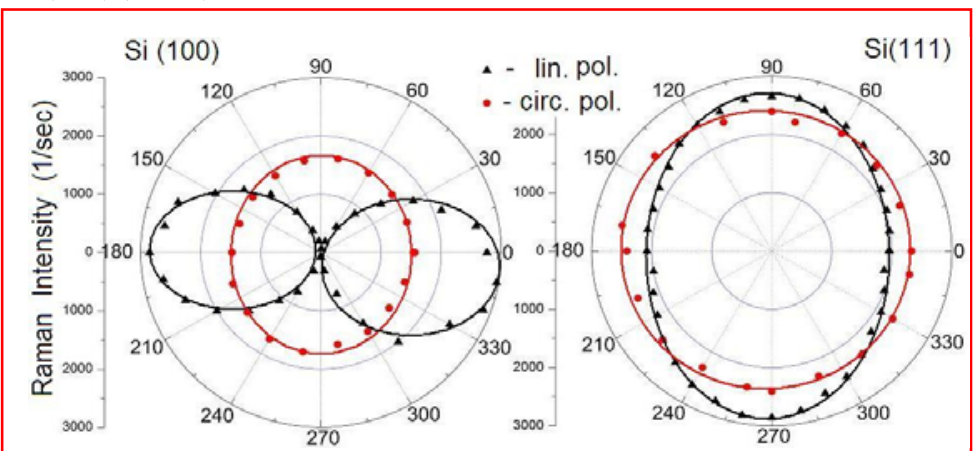

Рис.1. - Уаловые зависимости интенсивности КР ЛП и ЦП света на оптических фононах $\mathrm{Si}$, полученные при отражении от (100) и (111) плоскостей.
При возбуждении спектра ЦП светом наблюдаются изотропные зависимости (рис.1). Это соответствует тому, что рассеянный свет является ЦП. Можно видеть, что площадь кривых, полученных для ЛП и ЦП света совпадает (рис.1), что означает сохранение интегральной интенсивности КР в этих двух случаях. В результате, основные особенности КР ЦП света наследуются от ЛП и тензора КР. Так, для (100) поверхности активны только LO фононы, имеющие нулевой УM, и при рассеянии ЦП света спиральность фотона не меняется. Для (111) случая проявляются также ТО фононы, имеющие УМ равный $\pm 2 \hbar$ [3]. В этом случае спиральность фотона меняется на противоположную.

Угловая зависимость, полученная при КР ЦП света от поверхности (110), обнаруживает существенно анизотропную форму, которая совпадает с суммой двух кривых, измеренных с помощью ЛП света. Это означает распад возбуждающего ЦП света на две независимые ЛП компоненты, которые рассеиваются на фононах. В результате, в этой плоскости низкой симметрии проявляется дихроизм.

[1] S.Y. Chen et al, Nano Lett., 15, 2526 (2015)

[2] S. Zhang et al, ACS Nano, 11, 10366 (2017)

[3] L Zhang and Q. Niu, Phys.Rev.Lett.,115, 115502(2015) 